\title{
Corrosion of Permanent Mold Cast Magnesium Alloy AJ62 in Automotive Environments
}

Fang $\mathrm{LI}^{1, \mathrm{a}}$, Jonathan BURNS ${ }^{1, \mathrm{~b}}$, Henry $\mathrm{HU}^{1, \mathrm{c},{ }^{*},}$, Xue-Yuan NIE ${ }^{1, \mathrm{~d}}$, Jimi TJONG ${ }^{2, \mathrm{a}}$

${ }^{1}$ Department of Mechanical, Automotive \& Materials Engineering, University of Windsor, Windsor, Ontario N9B 3P4, Canada

${ }^{2}$ Ford Powertrain Engineering Research \& Development Centre, Windsor, Ontario N9A 6X3, Canada

1,afangl@uwindsor.ca, 1,burnss@uwindsor.ca, 1,chuh@uwindsor.ca, ${ }^{1, d}$ xnie@uwindsor.ca, 2,ajtjong@ford.com

${ }^{*}$ Corresponding author

Keywords: Corrosion, Mg Alloy AJ62, Permanent Mold Casting, Microstructure.

\begin{abstract}
Permanent mold cast (PMC) AJ62 magnesium alloy exhibits a fine-grained microstructure in the thin section and a coarse-grained microstructure in the thick section. Microstructure of the PMC AJ 62 alloy was analyzed by using the Scanning Electron Microscopy (SEM). Potentiodynamic polarization experiments were performed to investigate the corrosion resistances of the PMC AJ62 alloys in salt solutions and engine coolant. The corrosion behaviors in the fine- and coarse-grained AJ62 alloys were compared. The results show that the AJ62 alloy with fine microstructure presents enhanced corrosion resistance.
\end{abstract}

\section{Introduction}

Benefiting from their low density, magnesium alloys exhibit the greatest strength-to-weight ratio of any engineering structural metals [1]. One alloy that has been successful in this regard is the $\mathrm{Mg}-\mathrm{Al}-\mathrm{Sr}$ alloy $\mathrm{AJ} 62$. Its unique microstructure includes an $\mathrm{Al}_{4} \mathrm{Sr}$ intermtallic at the interdendritic regions rather than the $\mathrm{Mg}_{17} \mathrm{Al}_{12}$ common to other magnesium-aluminum alloys. Previous studies [1-4] indicating the creep resisting mechanisms of this microstructure tout this alloy's elevated temperature superiority among magnesium alloys.

The majority of magnesium alloy automotive application is in high-pressure die-cast (HPDC) components. This processing prohibits many designs that include heat-treating [5] and thicker cast sections due to the formation of a skin layer, subsurface defect band, coarse microstructure, and shrinkage porosity[6-8]. Good castability has characterized the AJ62 alloy in HPDC experiments leading to investigation of alternate processing. Permanent mould casting (PMC), a gravity-fed process offers thick casting sections potentially suitable for heat-treated components. While unable to offer the economies of scale achievable through high volume HPDC production, the PM process would yield a greater range of applicability available at a lower overhead and upfront tooling cost. Integral to an alloy's adaptation to a new process is the characterization of the alloy's performance in a number of potential environments. Magnesium's susceptibility to corrosion is a cause for concern in many operating environments [9]. Thus the observed response of permanent mould cast AJ62 microstructures to corrosion is of particular interest to the automotive industry. Here, the corrosion of the PMC AJ62 alloy in two media common to automotive environments, engine coolant and salt solution, has been documented and compared.

\section{Experimental Procedure}

Four (4)-step castings of magnesium alloy AJ62 $(6.00 \% \mathrm{Al}, 2.28 \% \mathrm{Sr}, 0.28 \% \mathrm{Mn}, 0.02 \% \mathrm{Si}$, others $<0.01 \%$, mass fraction) were produced via the permanent mould casting process in a steel mould. Four sections with different thicknesses $(4 \mathrm{~mm}, 6 \mathrm{~mm}, 10 \mathrm{~mm}$, and $20 \mathrm{~mm})$ were cast in one step casting. Of these, the two extreme thicknesses of $4 \mathrm{~mm}$ and $20 \mathrm{~mm}$ were subsequently sectioned taking a rectangular coupon from the centre of each. These samples were polished with abrasive 
papers up to 600 grit. This was done to avoid trapping bubbles of evolved hydrogen gas on the surface and to expose the microstructure to the electrolytic medium. Once prepared, the samples were assembled into an apparatus for potentiodynamic testing and subjected to polarisation tests one at a time with the first medium: a $0.5 \%$ sodium chloride solution. Polishing and testing were repeated again twice for each sample to observe the response to other electrolytes: a $1.0 \%$ sodium chloride solution and a commercial engine coolant. The coolant used was Prestone ${ }^{\circledR}$ antifreeze engine coolant suited for use in any make or model and to be mixed with any other coolant. This product was chosen to represent the commercially available generic engine coolants. The potentiodynamic testing apparatus included a Bio-Logic potentiostat connected to the sample, or working electrode (WE), and two other electrodes suspended in the electrolyte: a counter electrode (CE) placed directly above the sample surface, and a reference electrode (RE) located elsewhere in the electrolyte. Before beginning each test, the open circuit potential $\left(\mathrm{E}_{\mathrm{oc}}\right)$ was allowed to converge on a single value. The test was executed recording the current density (I) required to sustain a potential drop (E) ranging from $0.5 \mathrm{~V}$ below the Eoc to $-0.5 \mathrm{~V}$ with respect to the RE. More details on casting and corrosion experiments are given in references 9-12.

\section{Results and Discussion}

Microstructure of the permanent mould cast alloy includes $\mathrm{Mg}$ rich $\alpha$ matrix (A) and the $\mathrm{Al}_{4} \mathrm{Sr}$ intermetallic (B) in between the dendrite arms with intracellular Al-Mn particles (C). The microstructure as observed in the $20 \mathrm{~mm}$ thick section is presented in Figure 1. These alloy constituents have been confirmed by energy dispersive x-ray spectroscopy (EDS) in previous work [12]. The difference in microstructure between the $4 \mathrm{~mm}$ and $20 \mathrm{~mm}$ sections include greater secondary dendrite arm spacing (SDAS), less continuous intermetallic material, and less area percent intermetallics exhibited in the $20 \mathrm{~mm}$ section. This can be observed comparing the micrographs of Figure 2. Intermetallic continuity, on which immersion test results are often dependent because of micro-galvanic corrosion, is of less importance for the polarisation testing. Of greater consequence are the SDAS and the area percent intermetallic on the corroding surface. A visual comparison of these values for the two section thicknesses can be made from the graph in Figure 3.

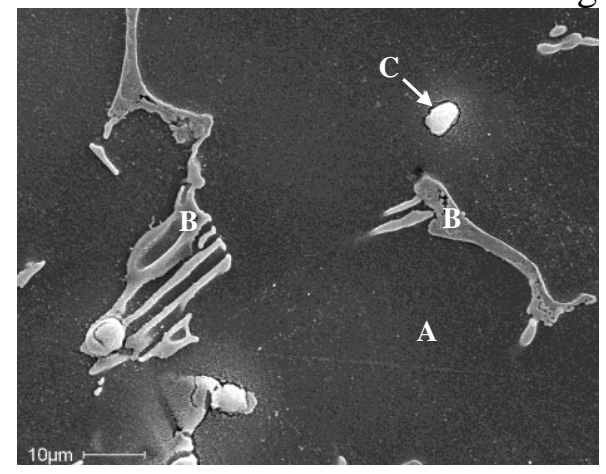

Fig. 1 Microstructure of the $20 \mathrm{~mm}$ section

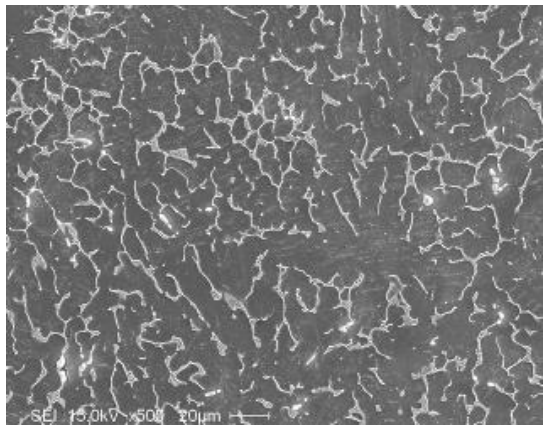

(a)

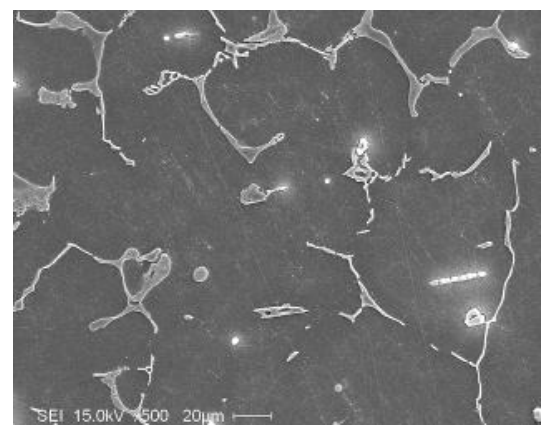

(b)

Fig. 2 SEM image of the (a) 4 and (b) $20 \mathrm{~mm}$ sections 


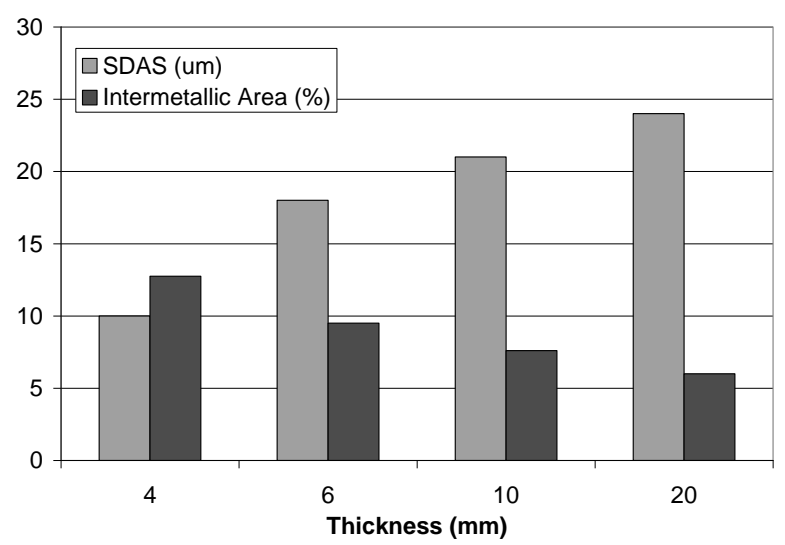

Fig. 3 SDAS and area percent intermetallic

Using the $0.5 \%$ and $1.0 \% \mathrm{NaCl}$ solutions as the electrolytic media for potentiodynamic testing, the response to polarization of the two microstructures was observed as in Figure 4. Critical values describing these curves have been presented in Table 1. Noteworthy was the dependency of the current density for ion exchange at the open circuit potential. Given a higher concentration of chloride ions, the difference in the current density between the different microstructures became less noticeable albeit on a small scale. This tendency is most likely due to the aggressive rate of corrosion in aqueous salt solution. In increasingly detrimental environments, the small microstructural variations have a lessened effect on the corrosion.

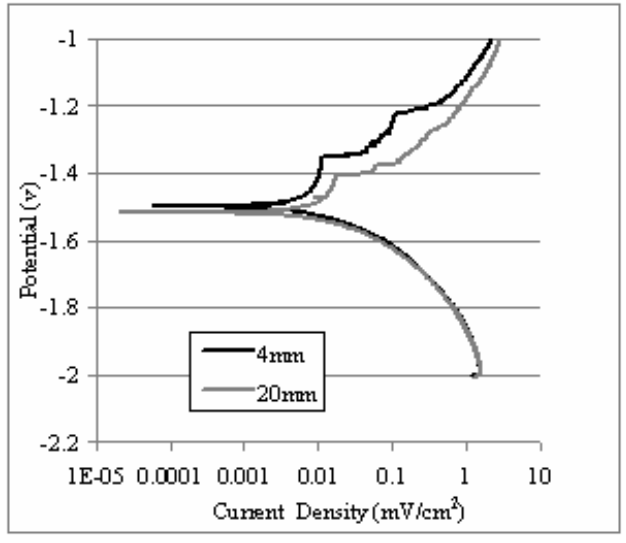

(a)

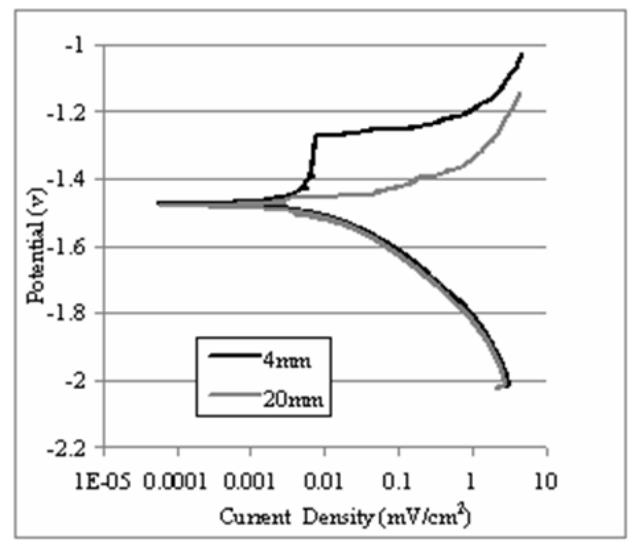

(b)

Fig. 4 Potentiodynamic polarisation curves in (a) $0.5 \%$ and (b) $1.0 \% \mathrm{NaCl}$ [13]

Tab. 1 Critical values pertaining to Figure 4

\begin{tabular}{|c|l|c|c|c|c|c|}
\hline \multicolumn{2}{|c|}{} & $\begin{array}{c}\beta_{\mathrm{A}} \\
(\mathrm{V})\end{array}$ & $\begin{array}{c}\beta_{\mathrm{C}} \\
(\mathrm{V})\end{array}$ & $\begin{array}{c}\mathrm{i}_{\text {corr }} \\
\left(\mu \mathrm{A} / \mathrm{cm}^{2}\right)\end{array}$ & $\begin{array}{c}\mathrm{E}_{\text {corr }} \\
(\mathrm{V})\end{array}$ & $\begin{array}{c}\mathrm{R} \\
\left(\mathrm{k} \Omega \bullet \mathrm{cm}^{2}\right)\end{array}$ \\
\hline \multirow{2}{*}{$0.5 \% \mathrm{NaCl}$} & $4 \mathrm{~mm}$ Sample & 0.067 & 0.046 & 2.254 & 1.498 & 5.23 \\
\cline { 2 - 7 } & $20 \mathrm{~mm}$ Sample & 0.066 & 0.045 & 3.311 & 1.516 & 3.51 \\
\hline \multirow{2}{*}{$1.0 \% \mathrm{NaCl}$} & $4 \mathrm{~mm}$ Sample & 0.065 & 0.040 & 1.342 & 1.472 & 8.01 \\
\cline { 2 - 7 } & $20 \mathrm{~mm}$ Sample & 0.065 & 0.039 & 1.463 & 1.480 & 7.21 \\
\hline
\end{tabular}

The variation in the current density observed when fewer chlorides are in the electrolytic solution is due to the area percent intermetallic. In general, the area comprised of $\alpha$ matrix is the working surface from which the positively charged ions are preferred to flow. Therefore the thicker section, having a coarser microstructure and less intermetallic area, has a greater working surface area than the thinner casting section for a given area on the specimen surface. Higher chloride concentrations have the effect of reducing the microstructure-influenced difference in current density. This is due to the chlorides in solution promoting movement of ions in solution thus facilitating accelerated hydrogen and/or oxide production reactions. 
Corrosion potential, $\mathrm{E}_{\mathrm{corr}}$, of the two microstructures also became more similar as the percent $\mathrm{NaCl}$ of the solution was increased. In the case of magnesium and its alloys this value is often near $-1.4 \mathrm{~V}$ resulting from its extreme anodic behaviour [12-14]. For the thicker casting section studied, its greater percent area $\alpha$ yields a more electronegative surface as this matrix has a significantly lower corrosion potential than the intermetallic materials. In fact, the corrosion potentials of the $\alpha$ magnesium and $\mathrm{Mg}_{17} \mathrm{Al}_{12}$ intermetallic are approximately $-1.3 \mathrm{~V}$ and $-0.9 \mathrm{~V}$ with respect to the standard hydrogen electrode in $\mathrm{NaCl}$ solution, having an effect shown clearly in the $0.5 \% \mathrm{NaCl}$ solution. In the $1.0 \% \mathrm{NaCl}$ solution, however, this is less noticeable. This too was attributed to the severity of the corrosion process as hydrogen production and oxide deposits on the surface generated more rapidly in the stronger solution may be masking the variation between the fine and coarse microstructures.

Finally, the passivation behaviour of the microstructure was observed. Magnesium is widely accepted as a well passivating metal. It has been documented to have significant corrosion resistance in air that is largely attributed to its passivating behaviour [9, 12, 14]. Expelled magnesium cations, $\mathrm{Mg}^{2+}$, react with hydroxyl anions, $(\mathrm{OH})^{-}$, leftover from the cathodic hydrogen evolution reaction to form magnesium hydroxide $\mathrm{Mg}(\mathrm{OH})_{2}$. In aqueous solution, this passive layer of magnesium hydroxide is only stable at high $\mathrm{pH}$. Most common environments for application are not so basic and in $\mathrm{NaCl}$ solution, chlorides promote the movement of the charged magnesium ions away from the surface. Thus, it is no surprise that the passive regions existing on the polarisation curves are observably small. Passivation, and the breakdown thereof, are phenomena dependent upon a number of seemingly uncontrollable variables, very local $\mathrm{pH}$ being a good example, and are often characterized by a level of unpredictability. A good demonstration of this is the near immediate breakdown of passivation observed with the $20 \mathrm{~mm}$ sample in the $1.0 \% \mathrm{NaCl}$ solution.

The response of an alloy to engine coolant is a far more complex concept than the response to $\mathrm{NaCl}$ solution. This is not only because engine coolants contain between 30 and $70 \%$ ethylene glycol to avoid freezing in cold climates, but because many inhibitors are also present $[12,15]$. The chemical additions used, and number of them, also vary from one coolant producer to another and are not information readily disclosed. Polarisation curves generated by the aforementioned methodology for AJ62 in a commercial engine coolant are presented in Figure 5. Accompanying values that characterize the curves are given in Table 2. Continuing with the theme proven in research using $\mathrm{NaCl}$ solutions that lower chloride concentrations will accentuate the differences between the varied microstructures, the three most easily noted characteristics of the polarisation curve were examined: current density, electrochemical potential, and passivation.

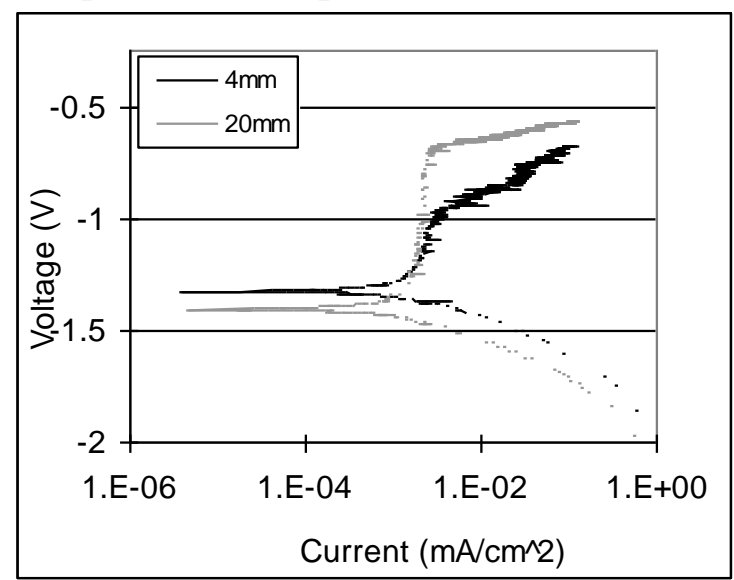

Fig. 5 Potentiodynamic polarisation curves in coolant

Current density for ion exchange at Ecorr, representative of the physical corrosion rate, is far lower than the values observed in $\mathrm{NaCl}$ solution. Anodic inhibitors in the engine coolant are primarily responsible for this behaviour. Blocking the movement of ions from the surface [9, 15], these chemical additions clearly do their job. With a lowered chloride concentration, the expectation is to see a large difference in the current density between the fine and coarse microstructures. This 
variation, however, is less noticeable than that observed in the salt solutions, which is counterintuitive. Again this behaviour is due to the inhibitors present in the coolant. Since the mechanism by which they afford protection of the alloy is to stop anodic behaviour at the anodic surface, the area of that surface becomes irrelevant if the concentration of inhibitors is sufficient. Therefore the variation in current density cannot be attributed as was previously to the difference in percent area $\alpha$ magnesium.

Tab. 2 Critical values pertaining to Figure 5

\begin{tabular}{|c|c|c|c|c|c|}
\hline Specimen & $\mathbf{I}_{\text {corr }}\left(\mathbf{m A} / \mathbf{c m}^{\mathbf{2}}\right)$ & $\mathbf{E}_{\text {corr }}(\mathbf{V})$ & $\boldsymbol{\beta}_{\mathbf{A}}$ & $\boldsymbol{\beta}_{\mathbf{C}}$ & $\mathrm{R}\left(\mathrm{k} \Omega \bullet \mathrm{cm}^{2}\right)$ \\
\hline $4 \mathrm{~mm}$ & 0.199 & -1.329 & 56.7 & 37.2 & 49.0 \\
\hline $20 \mathrm{~mm}$ & 0.213 & -1.409 & 76.7 & 36.1 & 50.0 \\
\hline
\end{tabular}

$\mathrm{E}_{\text {corr }}$ values are changed very little in the engine coolant as it appears in the same range near-1.4 V. What has changed is the variation between the $\mathrm{E}_{\text {corr }}$ for the fine and coarse microstructures. Inhibitors, as they were described above, stop flow of ions but do not change the electrochemical potential of the metal they are protecting. In the engine coolant, without the oxides forming as in water or salt solution, the true effect of $\alpha$ area versus intermetallic area is clearly seen. Having a surface heavily populated with the anodic metal clearly influences the $\mathrm{E}_{\mathrm{corr}}$ and this is not masked by severe corrosion in the case of engine coolant.

Lastly, the relevant discussion must include the passivation behaviour in the engine coolant. As well as containing additions to stop ion migration away from the surface, additions in engineered engine coolants are clearly used to promote passive behaviour. This can be seen above the $\mathrm{E}_{\text {corr }}$ on the curves in Figure 5 where the passive regions are appreciably larger than those seen using the $\mathrm{NaCl}$ solutions. Characterizing these regions is a "jagged" appearance especially noticeable well above the $\mathrm{E}_{\text {corr. }}$ This may be a result of a pitting corrosion response to the polarisation or non-uniform development of the passive film that can lead to a transfer of anodic behaviour from one region to another. The latter hypothesis is based on a potentially detrimental affect similar to the micro-galvanic effect that has been documented [9]. If local variations in the passive film can induce a pseudo micro-galvanic effect, its effects are likely seen in the response to polarisation as well. Whatever the cause of this passive region characteristic, its mechanism most likely operates in a localized manner. Ignoring the "jagged" appearance of the passive region, it is clear that the passivation is more prominent in the thicker section with coarser microstructure. Passivation occurs on the active anode and since the anodic area is larger for the coarser microstructure, passivation is achievable on a greater area for the $20 \mathrm{~mm}$ casting section.

\section{Summary}

The microstructure of the as-cast PMC AJ62 alloy consists of the primary $\alpha-\mathrm{Mg}$, eutectic $\mathrm{Al}_{4} \mathrm{Sr}$ phase, and Al-Mn particles. The fine microstructures are found to form in the thin section of the casting due to a high cooling rate while the coarse grains are present in the thick part.

The coarse microstructure resulted in the high corrosion current density in both $0.5 \%$ and $1.0 \%$ salt solutions with almost no change in the corrosion potential values for either fine or coarse microstructures. This is because the thicker section, having a coarser microstructure and less intermetallic area, has a working surface area (primary $\alpha-\mathrm{Mg}$ ) greater than the thinner casting section for a given area on the specimen surface.

Although the corrosion potential values of the fine and coarse-grained samples are almost the same in the salt solutions, the measured corrosion current density of the PMC AJ62 alloy in the coolant is obviously lower than that of the alloy in the salt solutions. The presence of inhibitors in the coolant should be responsible for the reduction in the corrosion current density.

The microstructure seems to have little influence the corrosion resistance of the PMC AJ62 alloy in the $1.0 \%$ salt solution and the engine coolant. However, the fine microstructure sample exhibits a corrosion resistance value $\left(5.23 \Omega \mathrm{cm}^{2}\right)$ higher than the coarse microstructure sample $\left(3.51 \Omega \mathrm{cm}^{2}\right)$ in the $0.5 \%$ salt solution, which has a low concentration of chloride ions. 


\section{Acknowledgement}

The authors would like to thank the Natural Sciences and Engineering Research Council of Canada, and University of Windsor for supporting this work.

\section{References}

[1]H. Hu, A. Yu, N. Li, J.E. Allison, Potential magnesium alloys for high temperature die cast automotive applications: a review, Materials and Manufacturing Processes. 185 (2003) 687-717.

[2]E. Baril, P. Labelle, M.O. Pekguleryuz, Elevated temperature Mg-Al-Sr: creep resistance, mechanical properties, and microstructure, Journal of Materials. 5511 (2003) 34-39.

[3]M. Kunst, A. Fischersworring-Bunk, G. L'Esperance, P. Plamondon, U. Glatzel, Microstructure and dislocation analysis after creep deformation of die cast $\mathrm{Mg}$-Al-Sr (AJ) alloy. Materials Science and Engineering A, 510-511 (2009) 387-392.

[4]M.O. Pekguleryuz, A.A. Kaya, Creep resistant magnesium alloys for powertrain applications,. Advanced Engineering Materials, 512 (2003) 866-878.

[5]R.N. Lumley, R.G. O’Doenell, D.R. M. Gunasegaram, Givord, New heat treatment for Al high pressure die castings, Heat Treating Progress. (2006) 31-37.

[6]A.K. Dahle, S. Sannes, D.H. St. John, H. Westengen, Formation of defect bands in high pressure die cast magnesium alloys, Journal of Light Metals. 1 (2001) 99-103.

[7]J.P. Weiler, J.T. Wood, R.J. Klassen, R. Berkmortel, G. Wang, Variability of skin thickness in an AM60B magnesium alloy die-casting, Materials Science and Engineering A. 419 (2006) 297-305.

[8]M. Zhou, H. Hu, N. Li and J. Lo, Microstructure and tensile properties of squeeze cast magnesium alloy AM50, 14 4, (2005) Journal of Materials Engineering \& Performance, 539-545.

[9]H. Hu, X. Nie and Y. Ma, Corrosion and surface treatment of magnesium alloys, in: F.Czerwinski (Ed.) Magnesium Alloys - Properties in Solid and Liquid States, In-Tech, Croatia, 2014, pp.67-108.

[10]Z. Sun, H. Hu, J.R. Burns, X. Nie, L. Han, Design of a Step Permanent Mould for Casting Magnesium Alloy AJ62, 118, (2010) AFS Transactions, 712-719.

[11]Zhang, P., Nie, X., Hu, H., Liu, Y., TEM analysis and tribological properties of Plasma Electrolytic Oxidation (PEO) coatings on a magnesium engine AJ62 Alloy, 205 (2010) Surface and Coatings Technology, 1508-1514.

[12]L.H. Han, X.Y. Nie and H. Hu, Electrochemical behaviour of squeeze cast AJ62 magnesium alloy in salt solution and engine coolant, Materials Technology, 24 (2009) 170-173.

[13]J.R. Burns, L. Han, H. Hu, X. Nie, Effects of section thicknesses on tensile properties of permanent mould cast magnesium alloy AJ62, Magnesium Technology 2010, The Minerals, Metals, and Materials Society. (2010) 367-371.

[14]G.L. Makar, J. Kruger, Corrosion of magnesium, International Materials Reviews, 382 (1993) 138-153.

[15]G. Song, D. StJohn, Corrosion behaviour of magnesium in ethylene glycol, Corrosion Science. 46 (2004) 1381-1399. 